\title{
Terson syndrome and leukemia: a case report
}

\author{
Umberto Lorenzi \\ Elisa Buschini \\ Antonio Fea \\ Federica Machetta \\ Federico Maria Grignolo \\ Ophthalmic Section, Department \\ of Clinical Pathophysiology, University \\ of Turin, Turin, Italy
}

This article was published in the following Dove Press journal:

Clinical Ophthalmology

03 April 2014

Number of times this article has been viewed

Background: Terson syndrome is defined as intraocular hemorrhage associated with intracranial bleeding. This syndrome can occur in the event of intracranial hemorrhage or elevated intracranial pressure. To our knowledge, it has never been associated with chronic myeloid leukemia. A 45-year-old woman suffering from chronic myeloid leukemia was referred to our clinic with Terson syndrome after intracranial bleeding. We followed this patient for a year, performing visual acuity assessment, fundus examination, color retinography, and A-scan and B-scan ultrasonography. At presentation, her best-corrected visual acuity on the right was 20/63 and on the left was 20/320. In the right eye, retinoscopy showed blurring of the optic margins surrounded by retinal and preretinal hemorrhages, preretinal fibrosis of the optic disc along the vascular arcades, and perivascular retinal infiltrates. In the left eye, the optic disc was surrounded by retinal and preretinal hemorrhages, and massive fibrosis with hard exudates and severe preretinal hemorrhage were observed at the posterior pole. Roth spots and many circular hemorrhages were noted at the periphery of the retina. A-scan and B-scan ultrasonography did not show intraocular leukemic infiltration. The clinical picture remained stable over the following 12 months. In this patient, we observed the ophthalmoscopic features of chronic myeloid leukemia, but also coexistence of features typical of Terson syndrome. To our knowledge, no similar cases have been reported previously.

Keywords: retinal disease, chronic myeloid leukemia, eye hemorrhage, intracranial hemorrhage

\section{Introduction}

Terson syndrome is defined as intraocular hemorrhage associated with intracranial bleeding. It was first described as an intraretinal hemorrhage following subarachnoid hemorrhage, ${ }^{1,2}$ but it was subsequently noted that it could occur in any case of intracranial hemorrhage or elevated intracranial pressure, and includes accumulation of subretinal, retinal, preretinal (subhyaloidal), or vitreal blood. It is usually bilateral, and in most cases recovers spontaneously within a few months. Vitrectomy can be considered in the most severe cases. ${ }^{3}$

\section{Case report}

A 45-year-old woman suffering from intraocular hemorrhage associated with chronic myeloid leukemia complicated by subdural hematoma was referred to our institution. Chronic myeloid leukemia had been diagnosed 10 years earlier and the patient's comorbidities were treated arterial hypertension, hepatitis B virus positivity, and orally treated type 2 diabetes mellitus diagnosed 3 years earlier. At presentation, she was in blast crisis for the second time and the disease was rapidly progressing. She was hospitalized in the Hematology-Oncology Department, University of Turin, with a very low platelet count $\left(8,000 / \mathrm{mm}^{3}\right)$ and red cell count $\left(2,000 \mathrm{~mm}^{3}\right)$, asthenia, fever, and occipital headache radiating to the anterior parts. A severe subdural hematoma was discovered, with ventricular dilatation and signs of high intracranial pressure. She was treated with repeated platelet
Correspondence: Elisa Buschini Ophthalmic Hospital,Via Juvarra 19, Turin 10121 , Italy

Tel +390 II 5666185

Fax +39 011539024

Email elisa.buschini@tiscali.it 
transfusions and conservative medical therapy. The patient's condition improved slowly, with progressive reabsorption of the hematoma and normalization of ventricular morphology on brain computed tomography scan.

We followed up this patient for a year by assessment of visual acuity, fundus examination, color retinography, and A-scan and B-scan ultrasonography. The patient complained of visual impairment in the left eye since the onset of her neurological symptoms, and was referred to our clinic. At presentation, her best corrected visual acuity on the right was 20/63 and on the left was 20/320. Retinal examination of the right eye revealed blurring of the optic margins surrounded by retinal and preretinal hemorrhages, preretinal fibrosis starting from the optic disc and extending along the vascular arcades, and perivascular retinal infiltrates (Figure 1A). Massive fibrosis with hard exudates and severe preretinal hemorrhage were observed in the left eye at the posterior pole (Figure 1B). The optic disc was surrounded by retinal and preretinal hemorrhages. Roth spots and many circular and preretinal hemorrhages were noted at the retinal periphery (Figure 1C). The other ocular structures were within normal limits. Ocular tension was good (right, $20 \mathrm{mmHg}$; left, $17 \mathrm{mmHg}$ ).

A-scan and B-scan ultrasonography showed similar clinical features in both eyes, ie, an anechogenic vitreous cavity, a small increase in the thickness of the chorioretinal complex, and some minute retinal lines with higher reflectivity, likely representing hemorrhages. The patient was monitored for 12 months, with no changes in her clinical and functional characteristics.

\section{Discussion}

Hematological disorders such as leukemia are often complicated by hemorrhage. Ocular tissues can be involved, causing hyphema in the anterior chamber, vitreous hemorrhage, or retinal hemorrhage. The retina is compromised in more than $50 \%$ of patients with leukemia, with vessel tortuosity and dilatation seen in the early stages. Bleeding can subsequently occur in all layers and can be round or flame-shaped, and is usually associated with a white area (Roth's spots) consisting of leukemic cells, debris, platelets, or emboli. ${ }^{4}$

We found bilateral retinal hemorrhages in our patient which were particularly concentrated around the optic nerve head, and associated with intracranial bleeding (subdural hematoma). This presentation reflects the clinical features of Terson syndrome. We found a large quantity of intraocular blood in the retinal layers and in the preretinal space, accompanied by blurring of the optic nerve head margins, massive preretinal fibrosis along the vascular arcades, hard exudates, Roth spots, and perivascular retinal infiltrates. This clinical picture is not typical of leukemia and could also help us to hypothesize about the mechanisms of entry of blood in Terson syndrome. To date, several theories have been proposed to explain how blood spreads into the eye. The various theories could be correct or may complement each other. After an intracranial hemorrhage and the subsequent increase in intracranial pressure, blood was thought to pass towards the intervaginal space of the optic nerve (ie, Schwalbe spaces), occluding the central retinal vein and causing bleeding at the level of the optic disc. ${ }^{5}$ Other authors suggest that the increase in pressure is transmitted by the retinal vein system in the orbit, causing occlusion at the level of the retinochoroidal anastomosis and bleeding from the vascular arcades, away from the optic disc. ${ }^{6}$ Some authors have found that blood from retinal veins may spread and accumulate between the internal limiting membrane and Muller cells. ${ }^{7}$ Finally, based on recent findings, it has been proposed that blood may also enter subretinally near the macula. ${ }^{8}$ In our case, the clinical presentation seems to be consistent with the first hypothesis, given that blood and

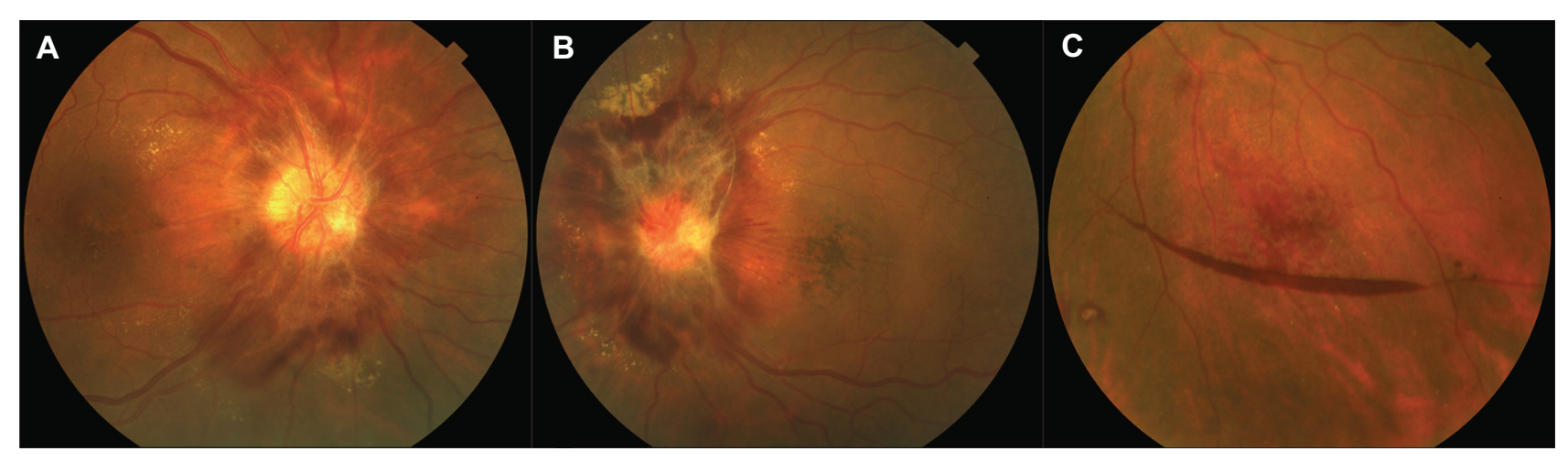

Figure I Terson syndrome: color retinography. (A, B) Posterior pole in the right and left eye. (C) Inferior retinal periphery in the left eye. 
consequent fibrosis were found to be concentrated around the optic disc.

Therapeutic management of Terson syndrome depends on the position of the intraocular hemorrhage. For a vitreous or subhyaloid hemorrhage, treatment could be conservative, ie, based on periodic observation awaiting spontaneous resorption, or more aggressive, ie, pars plana vitrectomy. In several cases, spontaneous improvement is observed within a few months from the acute event. Therefore, according to some authors, vitrectomy should be delayed and considered only in severe or bilateral cases that do not show signs of recovery. ${ }^{9}$ Surgical complications are generally rare, but they are possible and tend to be severe, even a long time after surgery (eg, retinal detachment and retinal tears, epiretinal membrane formation, cataract, macular hole formation, proliferative vitreoretinopathy, cystoid edema). However, a recent report suggests that early vitrectomy facilitates rapid and optimal visual recovery, thereby reducing the incidence of complications of vitreous hemorrhage (proliferative vitreoretinopathy and glaucoma). ${ }^{10}$ In conclusion, there are no clear specifications regarding surgical treatment in patients suffering from Terson syndrome. The optimal timing of surgery and functional outcomes are also uncertain. ${ }^{10}$

A surgical approach is not possible in the presence of intraretinal hemorrhage. Our patient presented with both intraretinal and preretinal hemorrhage. Because of this, combined with her poor general condition and the high risk of bleeding due to her low platelet count, a surgical approach could not completely resolve the problem and clinical management was oriented towards a conservative approach.

\section{Conclusion}

In this patient, we observed the ophthalmoscopic features of chronic myeloid leukemia and coexistence of features typical of Terson syndrome. To our knowledge, no similar cases have been previously reported.

\section{Disclosure}

The authors report no conflicts of interest in this work.

\section{References}

1. Litten M. [Ueber einige vom allegmein-klinischen Standpunkt aus interessante Augenveranderungen]. Berl Klin Wochnschr. 1881;18:23-27. German.

2. Terson A. [De 1'hémorrhagie dans le corps vitre au cours de l'hémorrhagie cerebrale]. Clin Ophthalmol. 1900;6:309-312. French.

3. Gnanaraj L, Tyagi AK, Cottrell DG, et al. Referral delay and ocular surgical outcome in Terson syndrome. Retina. 2000;20:374-377.

4. Sharma T, Grewal J, Gupta S, et al. Ophthalmic manifestations of acute leukaemias: the ophthalmologist's role. Eye. 2004;18:663-672.

5. Manschot WA. Subarachnoid hemorrhage; intraocular symptoms and their pathogenesis. Am J Ophthalmol. 1954;38:501-505.

6. Ogawa T, Kitaoka T, Dake Y. Terson syndrome: a case report suggesting the mechanism of vitreous hemorrhage. Ophthalmology. 2001; 108:1654-1656.

7. Arroyo JG, Bula DV. Immunohistochemical study of the internal limiting membrane in Terson syndrome. Retina. 2004;24:155-157.

8. Michalewska Z, Michalewski J, Nawrocki J. Possible methods of blood entrance in Terson syndrome. Ophthalmic Surg Lasers Imaging. 2010; 41(6):S42-S49.

9. Nacef L, Zghal-Mokni I, Allagui I, et al. Indications and results of vitrectomy in Terson syndrome. Tunis Med. 2004;82:461-464.

10. Garweg JG, Koerner F. Outcome indicators for vitrectomy in Terson syndrome. Acta Ophthalmol. 2009;87:222-226.
Clinical Ophthalmology

\section{Publish your work in this journal}

Clinical Ophthalmology is an international, peer-reviewed journal covering all subspecialties within ophthalmology. Key topics include: Optometry; Visual science; Pharmacology and drug therapy in eye diseases; Basic Sciences; Primary and Secondary eye care; Patient Safety and Quality of Care Improvements. This journal is indexed on

\section{Dovepress}

PubMed Central and CAS, and is the official journal of The Society of Clinical Ophthalmology (SCO). The manuscript management system is completely online and includes a very quick and fair peer-review system, which is all easy to use. Visit http://www.dovepress.com/ testimonials.php to read real quotes from published authors. 